\title{
Malignant bronchial ulcer with coexistent pulmonary tuberculosis
}

\author{
Yuvarajan Sivagnaname, Praveen Radhakrishnan, Antonius Maria Selvam \\ Department of Respiratory Medicine, Sri Manakula Vinayagar Medical College and Hospital, Pondicherry, India
}

\begin{abstract}
Ulceration in the bronchial mucosa is noted rarely in bronchoscopy. In the past, it was frequently encountered in endobronchial tuberculosis. Deep necrotic bronchial ulcers are seen very rarely in clinical practice. Here we are reporting a first-ever case report of malignant bronchial ulcer presenting as necrotic deep bronchial ulcer, in a 70-year-old male, chronic smoker, who complained of breathlessness for 3 months, cough for 3 months, loss of weight and of appetite for 1 month. Bronchoscopy showed a large necrotic ulcer with dense anthracotic pigmentation which bleeds in touch with forceps. Bronchial washings, brushings, endobronchial biopsy were taken from the ulcer which was suggestive of poorly differentiated bronchogenic carcinoma. TBNA from the mediastinal nodes showed the features of caseous necrosis with granulomatous inflammation. Consequently, with the diagnosis of poorly differentiated carcinoma with pulmonary tuberculosis and COPD, the patient was started on anti-tuberculosis drugs, inhaled bronchodilators and referred to an oncologist for chemotherapy.
\end{abstract}

\section{Introduction}

Ulcerations in the bronchial mucosa are not common in bronchoscopy, unlike in endobronchial tuberculosis, besides ulcers in those conditions are usually superficial. Similar superficial ulcerations of bronchial mucosa were noted in patients with adult varicella pneumonia, which presents with deep bronchial ulcers and is associ-

Correspondence: Yuvarajan Sivagnaname, Department of Respiratory Medicine, Sri Manakula Vinayagar Medical College and Hospital, Room no. 99, Kalitheerthalkuppam, Madagadipet, Puducherry 605107, India. Mobile: +91.9789156785 .

E-mail: nsivagnaname@yahoo.com

Key words: Malignant bronchial ulcer; pulmonary TB; bronchogenic carcinoma.

Received for publication: 20 January 2019.

Accepted for publication: 20 November 2019.

${ }^{\circ}$ Copyright: the Author(s), 2019

Licensee PAGEPress, Italy

Monaldi Archives for Chest Disease 2019; 89:1037

doi: 10.4081/monaldi.2019.1037

This article is distributed under the terms of the Creative Commons Attribution Noncommercial License (by-nc 4.0) which permits any noncommercial use, distribution, and reproduction in any medium, provided the original author(s) and source are credited. ated with poor prognosis [1]; deep ulcers were also noted in patients with Wegener's granulomatosis [2] (Table 1). Here, we are reporting a first-ever rare case report in literature of bronchogenic carcinoma presenting with a deep necrotic bronchial ulcer on bronchoscopy.

\section{Case Report}

A 70-year-old male, chronic smoker with a history of 30 pack/years, came to our hospital with main complaints of breathlessness for 3 months, cough for 3 months, loss of weight and appetite for 1 month. Initially, he was evaluated by a general practitioner, with chest radiograph and basic blood investigations.

The patient was admitted in our hospital and investigated further. Chest radiograph showed diffuse heterogenous opacity involving bilateral lung fields with blunting of costophrenic angles and flattened diaphragm. Blood investigations were within normal limits except for leukocytosis with polymorph predominance. Sputum direct smear for acid fast bacilli was negative. Sputum gram stain showed gram positive cocci in chains.

Computed tomography of chest was done which showed nodular lesions in right upper lobe with fibrotic strands in the apex along with randomly distributed nodules with few mediastinal necrotic lymph nodes. Peribronchial thickening at the level of bronchus intermedius was also noted.

Then, a diagnostic bronchoscopy was performed, which showed large necrotic ulcer with dense anthracotic pigmentation and unhealthy bronchial mucosa at the right secondary carina which bleeds on touch with forceps. Bronchial washings, brushings, endobronchial biopsy were taken from the ulcer. Bronchial wash/brush cytology showed highly cellular smear composed of many reactive bronchial epithelial cells and atypical cells. The atypical cells are round to oval arranged in cohesive clusters and sheets with overlapping nuclei, attempted rossettoid with glandular pattern and scattered single cells suggestive of poorly differentiated bronchogenic carcinoma. Conventional Transbronchial needle aspiration (TBNA) from the mediastinal nodes in subcarinal station showed the features of caseous necrosis with granulomatous inflammation and the cartridge based nucleic acid amplification test (CBNAAT) was positive for Mycobacterium Tuberculosis. Hence, with the diagnosis of poorly differentiated carcinoma with pulmonary tuberculosis, the patient was started on anti-tuberculosis drugs on a daily regimen (rifampicin $450 \mathrm{mg}$, isoniazid $300 \mathrm{mg}$, pyrazinamide $1500 \mathrm{mg}$, ethambutol 1200 $\mathrm{mg}$ ) and referred to an oncologist for chemotherapy.

\section{Discussion}

The coexistence of pulmonary TB and bronchogenic carcinoma was first reported by Bayle in 1810 [3]. The simultaneous develop- 
Table 1. Case reports in literature on bronchial ulcers.

$\begin{array}{ll}\text { Study } & \text { Findings } \\ \text { Inokuchi et al. [1] } & \begin{array}{l}\text { A case of varicella pneumonia in a } 69 \text {-year-old woman with extensive mucosal airway ulcerations from the pharynx to the main bronchi } \\ \text { and numerous VZV-infected cells. The authors found that patients with limited or shallow ulcers had favorable outcomes, whereas } \\ \text { patients with vast and deep ulcerations had fatal outcomes. }\end{array} \\ \text { Pauls et al. [2] } & \begin{array}{l}\text { A 55-year-old male patient who presented with cough and fever posted for bronchoscopy revealed diffuse erythema of the } \\ \text { tracheobronchial mucosa with diffusely scattered white plaques. Histopathology described a multifocal ulcerative bronchitis with } \\ \text { underlying chronic bronchitis, night sweats and weight loss). These findings in combination with the laboratory data lead to the diagnosis } \\ \text { of Wegener's granulomatosis. }\end{array}\end{array}$

ment of unsuspected primary cancer in close vicinity to an active pulmonary tuberculous process can seriously complicate diagnosis, and in most reported cases, a long interval had elapsed before carcinoma was suspected [4].

Various reasons are proposed for association between pulmonary TB and lung cancer by different authors. One hypothesis would be that inflammation associated with infections can contribute to carcinogenesis [5]. Reactive oxygen or nitrogen species produced by activated neutrophils can bind to the DNA, inducing genetic damage and neoplastic transformation [6]. In fact, it has been shown that alterations of the fragile histidine triad gene might be involved in lung carcinogenesis in patients with chronic pulmonary tuberculosis [7-10]. In addition, during tissue repair, there is increased cell proliferation and angiogenesis, and the epithelium is more prone to metaplasia $[9,10]$.

Clinical diagnosis of co-existing TB and cancer is often challenging. This often causes a delay in diagnosis and institution of appropriate treatment and is associated with poor prognosis. Wofford et al. [10] reported 34 cases of coexisting carcinoma lung and pulmonary $\mathrm{TB}$ and reported the average delay in making the diagnosis when TB and cancer co-exist to be 13 months. Atypical course of TB, presence of pain, radiological evidence of rib erosion and ipsilateral hilar lymphadenopathy casts doubt on the possibility of coexistence of a malignancy.

TB has been known to complicate the course of cancer. Kaplan et al. [11] studied 201 patients with cancer who developed TB during the period 1945-1971. High TB prevalence was seen in patients with Hodgkin's disease and lung cancer compared to carcinoma bladder, carcinoma colon.

In our case, patient was diagnosed to have poorly differentiated bronchogenic carcinoma along with coexistent pulmonary tuberculosis. Co-existence of tuberculosis and cancer causes diagnostic dilemma due to the similarities in presentation, leading to delay in the diagnosis and institution of appropriate therapy. Patients with lung cancer are also vulnerable to develop active pulmonary TB due to immunosuppression and malnutrition resulting from the use of intensive treatment modalities such as aggressive chemotherapy.

\section{Conclusions}

Even though clinical radiological features suggest tuberculosis, malignancies can coexist with tuberculosis, and this occur- rence should be kept in mind while evaluating the patient. Usually, bronchogenic carcinoma usually presents as endobronchial or parenchymal nodules. In our case it presented as deep bronchial necrotic ulcer along with coexistent pulmonary TB. To the best of our knowledge, this is the first case report of malignant bronchial ulcer in literature.

\section{References}

1. Inokuchi R, Nakamura K, Sato H, et al. Bronchial ulceration as a prognostic indicator for varicella pneumonia: case report and systematic literature review. J Clin Virol 2013;56:360-4.

2. Pauls S, Kruger S, Barth TF, et al. Atypical bronchial thickening and ulceration: a rare radiological finding in Wegener's granulomatosis. Br J Radiol 2007;80:e173-5.

3. Bayle CH. Recherches sur la phitisue pulmonaire. Galon, Paris; 1810.

4. Raeburn G, Spencer H. Lung scar cancer. Br J Tuberc Dis Chest 1957;51:237-45.

5. Harikrishna J, Sukaveni V, Kumar DP, Mohan A. Cancer and tuberculosis. JIACM 2012;13:142-4.

6. Lin WW, Karin M. A cytokine-mediated link between innate immunity, inflammation, and cancer. J Clin Invest 2007;117: 1175-83.

7. Nalbandian A, Yan BS, Pichugin A, et al. Lung carcinogenesis induced by chronic tuberculosis infection: the experimental model and genetic control. Oncogene 2009;28:1928-38.

8. Song L, Yan W, Deng M, et al. Aberrations in the fragile histidine triad (FHIT) gene may be involved in lung carcinogenesis in patients with chronic pulmonary tuberculosis. Tumour Biol 2004;25:270-5

9. Song L, Yan W, Zhao T, et al. Mycobacterium tuberculosis infection and FHIT gene alterations in lung cancer. Cancer Lett 2005;219:155-62.

10. Wofford JL, Webb WR, Stauss HK. Tuberculous scarRing and primary lung cancer. Clinical and aetiologic considerations. Arch Surg 1962;85:928-35.

11. Kaplan MH, Armstrong D, Rosen P. Tuberculosis complicating neoplastic disease. A review of 201 cases. Cancer 1974;33: 850-8. 